\title{
Influence of hot working conditions on grain growth behavior of Alloy 718
}

\author{
Chuya Aoki, Tomonori Ueno, Takehiro Ohno \\ Metallurgical Research Laboratory, Hitachi Metals, LTD., \\ 1240-2 Hashima, Yasugi, Shimane, Japan
}

Keywords: 718, abnormal grain growth, microstructure, strain, strain rate

\begin{abstract}
The grain growth behavior of Alloy 718 with emphasis on abnormal grain growth (AGG) has been investigated through compression tests and subsequent solution heat treatment. Imposing a small strain, where no recrystallization occurred, resulted in AGG during thermal process which involves solution heat treatment, annealing and slow cooling after deformation. AGG occurred beyond the $\delta$ particles, with the initial grain size of ASTM 10 coarsening to about ASTM 5. Both strain and strain rate during deformation had a great influence on AGG occurrence. AGG became remarkable with decreasing strain, and the strain range where it took place shifted to larger strains with decreasing strain rate. Particularly, deformation at a low strain rate of the order of $10^{-3} \mathrm{~s}^{-1}$ easily led to grain growth during solution heat treatment, over the strain range even where recrystallization occurred. Such grain growth was referred to as irregular grain growth (IGG) to distinguish it from AGG.
\end{abstract}

\section{Introduction}

Alloy 718 has been widely used for applications of aircraft engines and power generation turbines. These products frequently require the fine-grained structure because of emphasizing fatigue strength. Therefore, for manufacturing Alloy 718 , hot-working process which involves recrystallization and inhibiting grain growth by pinning effect of $\delta$ phase can provide a fine-grained structure, thereby demonstrating good tensile and fatigue properties.

On the other hand, AGG, when fine grains sometimes change into coarse grains with diameters of about $50 \mu \mathrm{m}$ or more, is a serious problem in producing fine-grained structure. It has been reported that a small strain during deformation caused AGG after annealing [1-8], decreasing the low cycle fatigue properties [4]. AGG is not a special phenomenon for Alloy 718, and it has also been reported for R'88DT $[5,6]$. It is necessary to pay close attention to AGG for closed-die forging because it is not easy to impose enough strain to avoid it for the whole area of material. In addition, the components of aircraft engines and power generation turbines tend to be made bigger in order to improve energy efficiency, and larger parts create process of challenges.

The objective of the study is to research the influences of various hot-working conditions on grain growth behavior of Alloy 718 with emphasis on AGG and to understand its behavior.

\section{Experimental procedures}

The Alloy 718 ingot was produced by vacuum induction melting (VIM), electro-slag remelting (ESR) and vacuum arc remelting (VAR), and then converted into billet with diameters of about $305 \mathrm{~mm}$. The chemical composition is given in Table 1 .
The Alloy 718 material was prepared by upset forging the billet into a pancake and subsequent ring rolling below $\delta$ solvus temperature. The microstructure was fully recrystallized, and the grain size was ASTM 10. Samples were cut from the ring rolled Alloy 718 such that the compression axis was parallel to the tangential direction, and then preheated at $980{ }^{\circ} \mathrm{C}$ for $1 \mathrm{hr}$ and machined according to Figure 1. Double cone geometry of Figure 1 was similar to work reported in the literature [2,5]. We investigated several influences on grain growth, including:

(1) Strain

(2) Strain rate

(3) Annealing time or cooling rate from deformation

(4) Solution heat treatment temperature after deformation

Test conditions are shown in Table 2. Use of the commercial software DEFORM ("DEFORM" is a trademark of Scientific Forming Technologies Corporation) with our original database for Alloy 718 determined the range of strain and strain rate in which grain coarsening took place. After compression tests, samples were solution heat treated, followed by air cooling. Samples in the as-deformed and after solution heat treatment were cut in half along the axial direction, and then prepared to evaluate microstructures by using optical microscope (OM), scanning electron microscope (SEM) and electron backscatter diffraction (EBSD). To understand the characteristics of microstructures along radial direction of samples, grain size, twin boundary density and intragranular misorientation were evaluated, with the measurement area being divided into several areas in the radial direction. These characteristics were determined by analyzing EBSD datasets using the TSL OIM analysis software. Grains were detected as groups of adjacent pixels with less than $15^{\circ}$ misorientation in the present paper. Therefore, twin boundaries were ignored in the grain detection. Twin boundary density was quantified as a length ratio of $\Sigma 3$ boundaries to total boundaries. For intragranular misorientation quantification, kernel average misorientation (KAM) was evaluated to know where misorientation was concentrated within each grain.

Table 1. Typical chemical composition of Alloy 718

\begin{tabular}{|c|c|c|c|c|c|c|c|}
\hline $\mathrm{C}$ & $\mathrm{Fe}$ & $\mathrm{Ni}$ & $\mathrm{Cr}$ & $\mathrm{Mo}$ & $\mathrm{Al}$ & $\mathrm{Ti}$ & $\mathrm{Nb}$ \\
\hline 0.023 & Bal. & 53.7 & 18.0 & 3.0 & 0.48 & 0.95 & 5.44
\end{tabular}




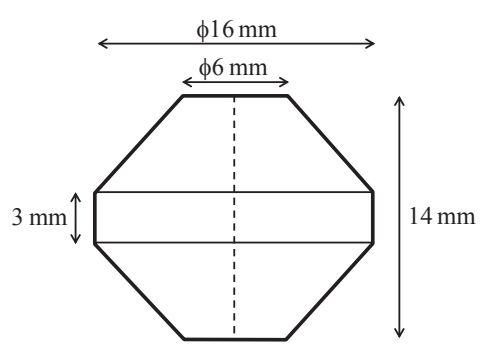

Figure 1. Geometry of double cone specimen

Table 2. Compression test and solution heat treatment conditions

\begin{tabular}{|l|l|}
\hline Test temperature & $980^{\circ} \mathrm{C}$ \\
\hline Reduction & $10,30,50 \%$ \\
\hline Nominal strain rate & $0.001,0.005,0.05,0.5,5 \mathrm{~s}^{-1}$ \\
\hline Cooling rate from deformation & $6,60,540{ }^{\circ} \mathrm{C} / \mathrm{min}$ \\
\hline Annealing time from deformation & $980^{\circ} \mathrm{C} / 0-240 \mathrm{sec}$ \\
\hline Annealing temperature from deformation & $900-980^{\circ} \mathrm{C} / 10 \mathrm{~min}$ \\
\hline S.T. after deformation & $980^{\circ} \mathrm{C} / 1 \mathrm{hr}$ \\
\hline
\end{tabular}

S.T. : Solution heat treatment

\section{Results}

\section{Initial microstructure}

The initial microstructures as-preheated at $980{ }^{\circ} \mathrm{C}$ for $1 \mathrm{hr}$ before deformation are shown in Figure 2a-b. The grain size is uniform ASTM 10, which is comparable to that as ring rolled. The $\delta$ particles, which account for about $5 \%$ area ratio, are almost homogeneously distributed.

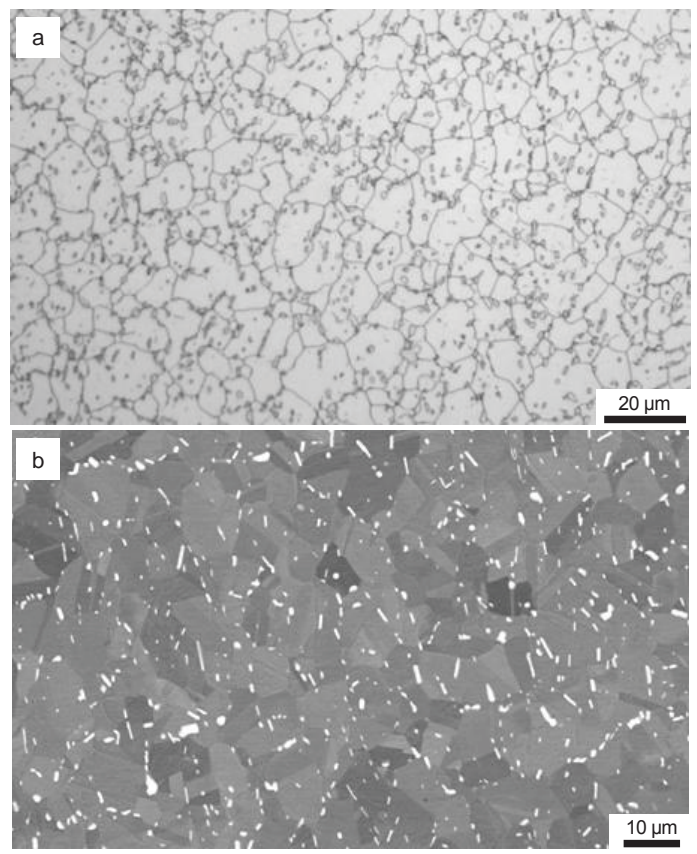

Figure 2. The initial microstructure (a) Optical micrograph, (b) BSE image
Influence of strain and strain rate on grain growth

Samples were deformed at $980{ }^{\circ} \mathrm{C}$ to various reduction (10 to $50 \%)$ at various nominal strain rates $\left(0.001 \mathrm{~s}^{-1}\right.$ to $\left.5 \mathrm{~s}^{-1}\right)$, followed by cooling at a cooling rate of $540{ }^{\circ} \mathrm{C} / \mathrm{min}$. Then the deformed samples were solution heat treated at $980{ }^{\circ} \mathrm{C}$ for $1 \mathrm{hr}$ and then air cooled.

Figure 3a-c show optical micrographs and a strain contour for the condition to $10 \%$ reduction at a nominal strain rate of $0.5 \mathrm{~s}^{-1}$. AGG occurs during solution heat treatment because the microstructure as-deformed condition is ASTM 10 comparable to the initial grain structure (Figure $3 \mathrm{a}$ and $3 \mathrm{~b}$ ). Comparing Figure $3 \mathrm{~b}$ with Figure $3 \mathrm{c}$ indicates that the coarse grains region corresponds to the strain range of 0.05 to 0.1 . Figure $4 a-b$ show the microstructure after solution heat treatment at the position corresponding to the strain of 0.05 which is a boundary between coarse grains region and fine grains region. It appears that the grain coarsening occurs beyond $\delta$ particles because $\delta$ particles are almost homogeneously distributed. Figure 5a-c show optical micrographs for the condition to $30 \%$ reduction at a nominal strain rate of $0.5 \mathrm{~s}^{-1}$. Increasing strain yields recrystallization in the strain range of about 0.3 or more. The recrystallized structure is also fine-grained structure after solution heat treatment. The region of ASTM 10 or less is observed in the strain range of 0.2 or less, and grain coarsening during solution heat treatment proceeds with decreasing strain. As shown in Figure 3 and 5, the coarse grains compared to the initial grain size of ASTM 10 are observed in the strain range of 0.05 to 0.2 in situations where a nominal strain rate is $0.5 \mathrm{~s}^{-1}$.

Figure 6a-c show optical micrographs for the condition to $30 \%$ reduction at a nominal strain rate of $0.005 \mathrm{~s}^{-1}$. Coarse grains are observed in the strain range of 0.16 or more, implying that the strain range where grain coarsening occurres shifts to larger strains in comparison to the case where the nominal strain rate is $0.5 \mathrm{~s}^{-1}$. For the microstructure as-deformed condition, recrystallization takes place in the strain range of about 0.25 or more. However, noteworthy is that the resultant fine-grained structure coarsens compared to the initial structure during solution heat treatment (Figure 6c). The behavior appears to be different from what is observed in Figure $5 \mathrm{c}$ in the case of normal grain growth after recrystallizarion. The coarsening was also observed at the position corresponding to strain of 1.2 or more for the microstructure which was solution heat treated after deformed to $50 \%$ reduction at a nominal strain rate of $0.005 \mathrm{~s}^{-1}$. A similar behavior is also observed on the condition that a nominal strain rate is $0.001 \mathrm{~s}^{-1}$, as can be seen from Figure $7 \mathrm{a}-\mathrm{c}$. Another feature is that the grain coarsening is partial relative to that for higher nominal strain rates.

Figure 8 illustrates grain size map for various strains and strain rates. The numbers in Figure 8 are grain size numbers after solution heat treatment at $980{ }^{\circ} \mathrm{C}$. The initial fine grains of ASTM 10 coarsen to ASTM 5- to 6 by solution heat treatment after deformation in which smaller strain is applied. AGG is reduced with increasing strain. In addition, the strain range where AGG takes place shifts to larger strains with decreasing strain rate. Especially, deformation at low strain rates of $0.05 \mathrm{~s}^{-1}$ or less results in grain coarsening not only for smaller strains but also for larger strains where recrystallization occurs. This tendency becomes remarkable with decreasing strain rate. A similar phenomenon has been reported by literature [9] as to isothermal forging of Alloy 718, and described as irregular grain 
growth (IGG). The generation mechanism of IGG may be the same as AGG. In the present paper, when grains coarsen up to ASTM 9 or less after recrystallization occurrence by deformation, such coarsening is referred to as IGG to distinguish it from AGG.
It is thought that the deformation under the conditions of strain more than about 0.4 and strain rate more than about $0.05 \mathrm{~s}^{-1}$ are required to avoid not only AGG but also IGG.
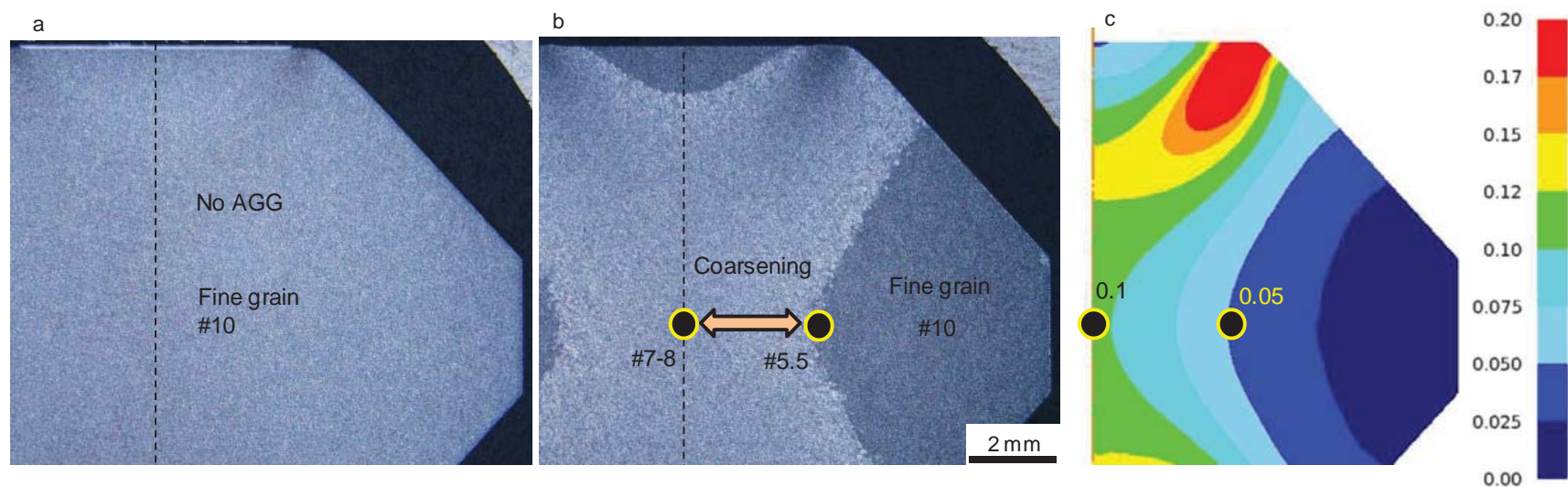

Figure 3. Optical micrographs and a strain contour for $10 \%$ reduction at a nominal strain rate of $0.5 \mathrm{~s}^{-1}$ Microstructures; (a) as-deformed at $980{ }^{\circ} \mathrm{C}$, and (b) solution heat treated at $980{ }^{\circ} \mathrm{C}$ after deformation
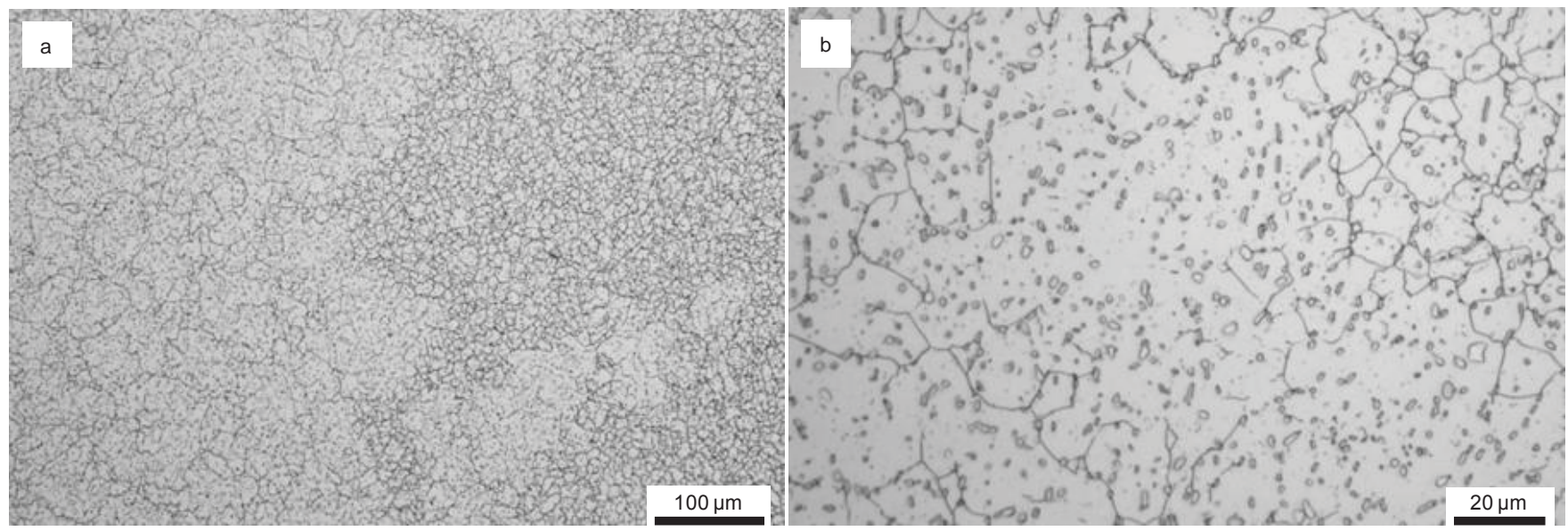

Figure 4. Optical micrographs after solution heat treatment at the position corresponding to the strain of 0.05 ; (a) low magnification, (b) high magnification
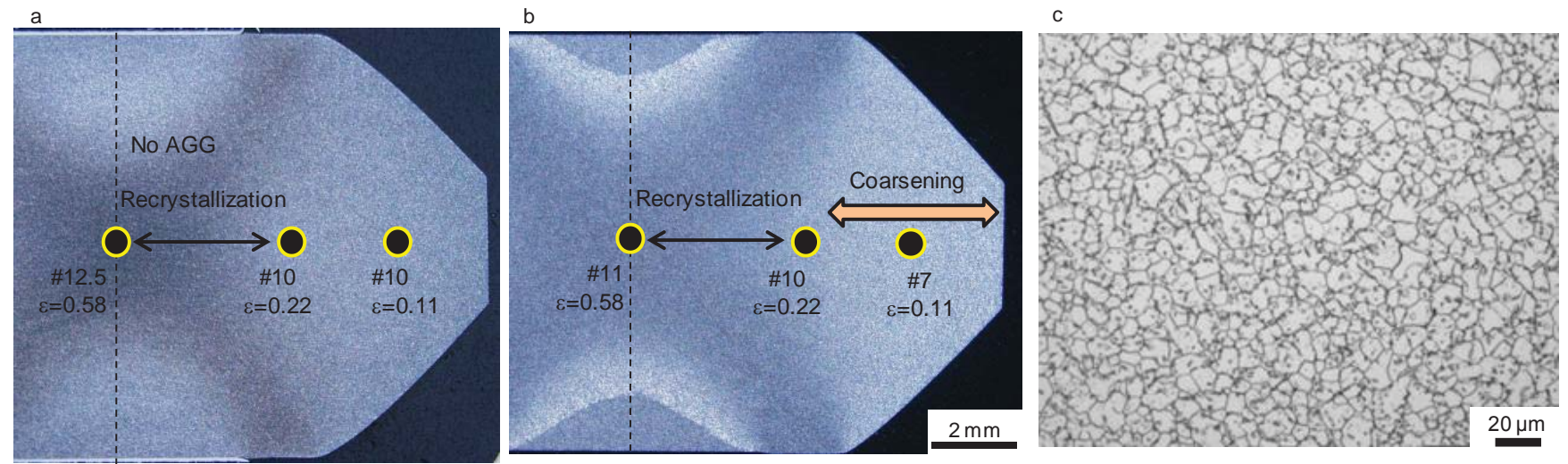

Figure 5. Optical micrographs for $30 \%$ reduction at a nominal strain rate of $0.5 \mathrm{~s}^{-1}$

Microstructures; (a) as-deformed at $980{ }^{\circ} \mathrm{C}$, and (b)(c) solution heat treated at $980{ }^{\circ} \mathrm{C}$ after deformation

(c) at the position corresponding to the strain of 0.58 

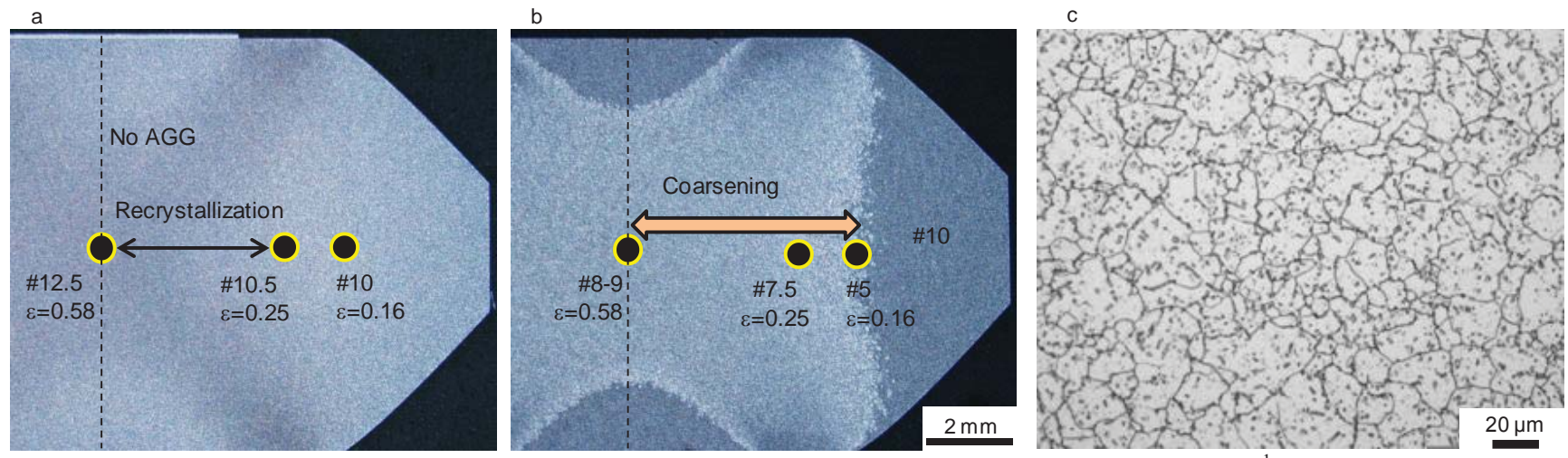

Figure 6. Optical micrographs for $30 \%$ reduction at a nominal strain rate of $0.005 \mathrm{~s}^{-1}$

Microstructures; (a) as-deformed at $980{ }^{\circ} \mathrm{C}$, and (b)(c) solution heat treated at $980{ }^{\circ} \mathrm{C}$ after deformation

(c) at the position corresponding to the strain of 0.58
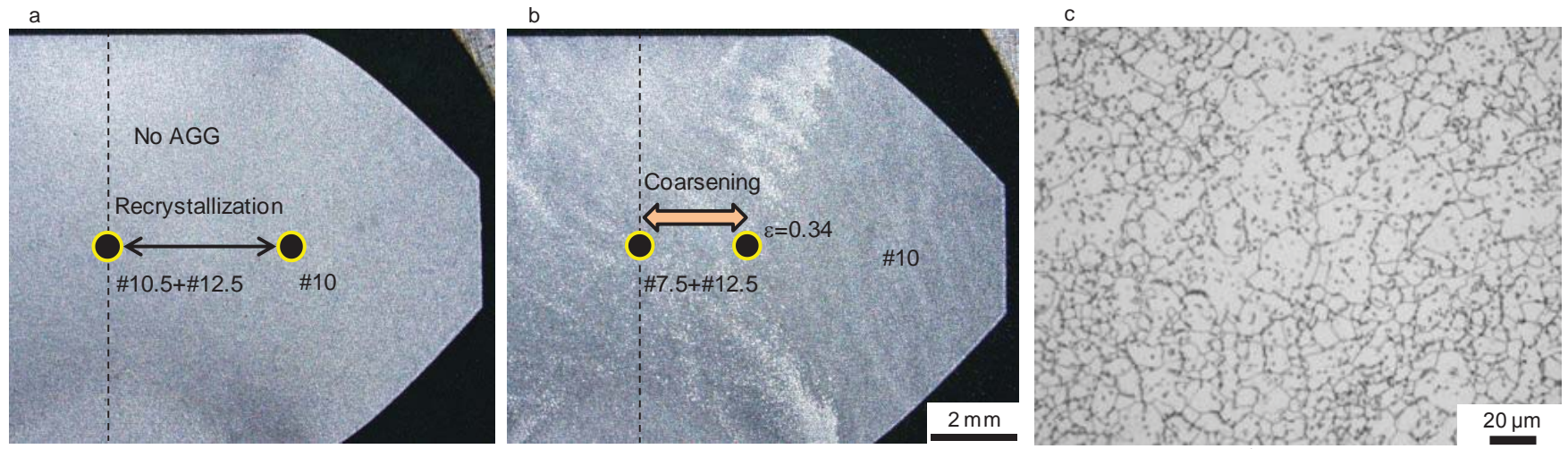

Figure 7. Optical micrographs for $30 \%$ reduction at a nominal strain rate of $0.001 \mathrm{~s}^{-1}$

Microstructures; (a) as-deformed at $980{ }^{\circ} \mathrm{C}$, and (b)(c) solution heat treated at $980{ }^{\circ} \mathrm{C}$ after deformation

(c) at the position corresponding to the strain of 0.34 or more

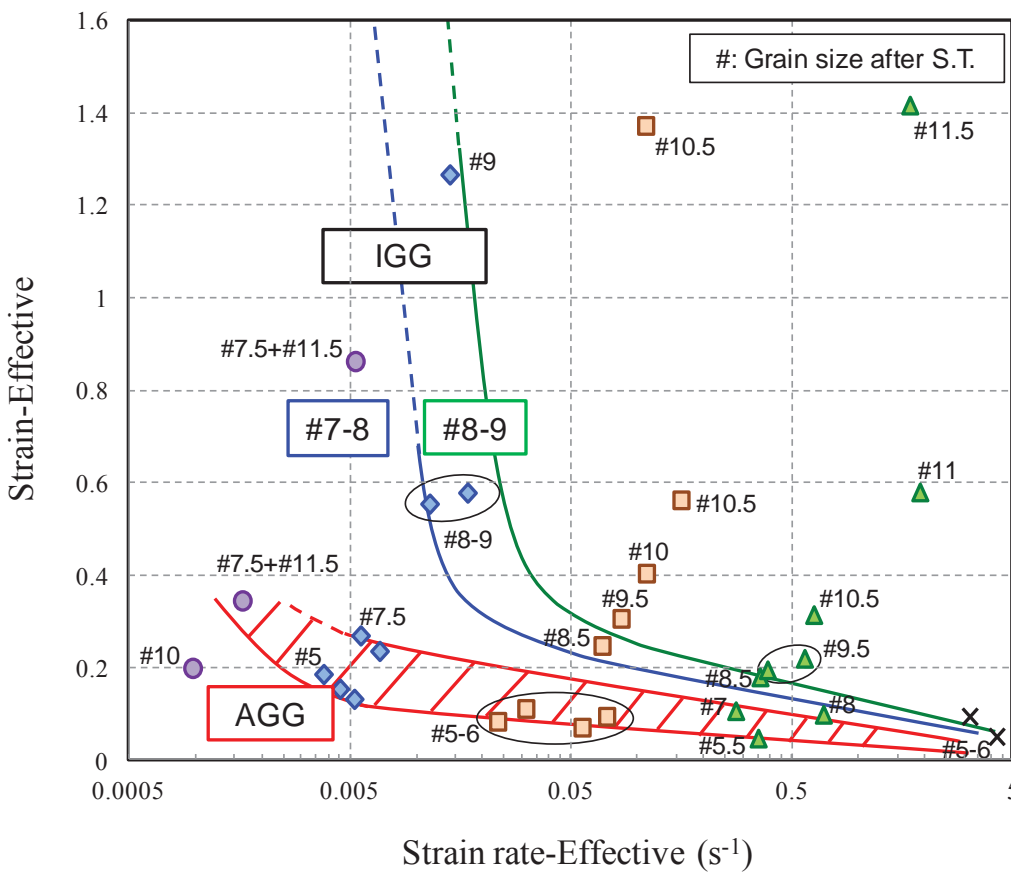

o Nominal strain rate: $0.001 / \mathrm{s}$

$\diamond$ Nominal strain rate: $0.005 / \mathrm{s}$

口Nominal strain rate: $0.05 / \mathrm{s}$

$\Delta$ Nominal strain rate: $0.5 / \mathrm{s}$

$\times$ Nominal strain rate:5/s

Compression test conditions Initial grain size : ASTM 10

Compression temperature : $980^{\circ} \mathrm{C}$

Reduction : 10,30, 50\%

Nominal strain rate : $0.001,0.005,0.05,0.5,5 \mathrm{~s}^{-1}$

Cooling rate from deformation : $540^{\circ} \mathrm{C} / \mathrm{min}$

Solution heat treatment

$980^{\circ} \mathrm{C} / 1 \mathrm{hr}$, air cooling

Figure 8. Grain size map for various strains and strain rates 
Influence of different cooling rates from deformation on AGG occurrence was investigated. Samples were compressed at 980 ${ }^{\circ} \mathrm{C}$ to $10 \%$ reduction at a nominal strain rate of $0.5 \mathrm{~s}^{-1}$, followed by controlled cooling to $700{ }^{\circ} \mathrm{C}$ at cooling rates between 0 (annealing at $980{ }^{\circ} \mathrm{C}$ for $10 \mathrm{~min}$ ) and $540{ }^{\circ} \mathrm{C} / \mathrm{min}$. As shown in Figure 9a-d, observation of microstructures as-deformed condition (without solution heat treatment) indicates that slow cooling rates of $60{ }^{\circ} \mathrm{C} / \mathrm{min}$ or less result in AGG occurrence. AGG appears to start from the strain position of about 0.1 for the strain range of 0 to 0.1 .

Influence of both annealing time and annealing temperature immediately after deformation on AGG occurrence was investigated. Samples were deformed at $980{ }^{\circ} \mathrm{C}$ to $10 \%$ reduction at a nominal strain rate of $0.5 \mathrm{~s}^{-1}$, followed by

annealing at $980{ }^{\circ} \mathrm{C}$ for between 10 and $240 \mathrm{sec}$, and by annealing at between 900 and $980{ }^{\circ} \mathrm{C}$ for $10 \mathrm{~min}$. Observation of microstructures as-deformed condition (without solution heat treatment) indicated that AGG proceeded with increasing annealing time and annealing temperature. Grain growth during both the annealing at $980{ }^{\circ} \mathrm{C}$ for $10 \mathrm{sec}$ and the annealing at 900 ${ }^{\circ} \mathrm{C}$ for 10 min was similar to Figure 9 b.

Influence of different solution heat treatment temperatures after deformation on AGG occurrence were investigated. Samples were compressed at $980{ }^{\circ} \mathrm{C}$ to $10-50 \%$ reduction at a nominal strain rate of $0.005 \mathrm{~s}^{-1}$, and then cooled at a cooling rate of 540 ${ }^{\circ} \mathrm{C} /$ min and solution heat treated at between 927 and $968{ }^{\circ} \mathrm{C}$ for 1 hr. Observation of microstructures indicated that solution heat treatment at $927^{\circ} \mathrm{C}$ almost inhibited not only AGG but also IGG.
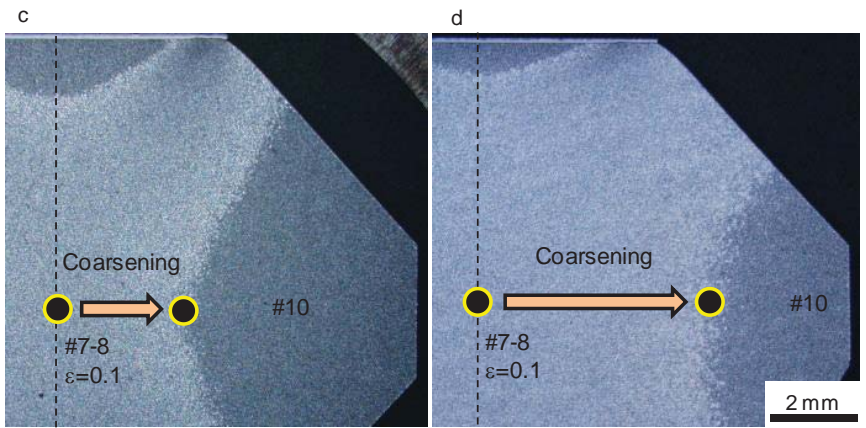

Figure 9. Optical micrographs as-deformed conditions to $10 \%$ reduction at a nominal strain rate of $0.5 \mathrm{~s}^{-1}$

Cooling rates from deformation; (a) $540{ }^{\circ} \mathrm{C} / \mathrm{min}$, (b) $60{ }^{\circ} \mathrm{C} / \mathrm{min}$, (c) $6{ }^{\circ} \mathrm{C} / \mathrm{min}$, and (d) $0{ }^{\circ} \mathrm{C} / \mathrm{min}$ (annealing at $980{ }^{\circ} \mathrm{C}$ for $10 \mathrm{~min}$ )

\section{Characteristic of AGG microstructure}

Figure 10a-b show grain boundary image and KAM map by EBSD analysis at the strain position of 0.1 in Figure 3a. Blue and red lines of Figure 10a are grain boundaries and twin boundaries, respectively. Comparing Figure 10a with Figure 10b indicates that misorientation concentrates mainly on near grain boundaries.

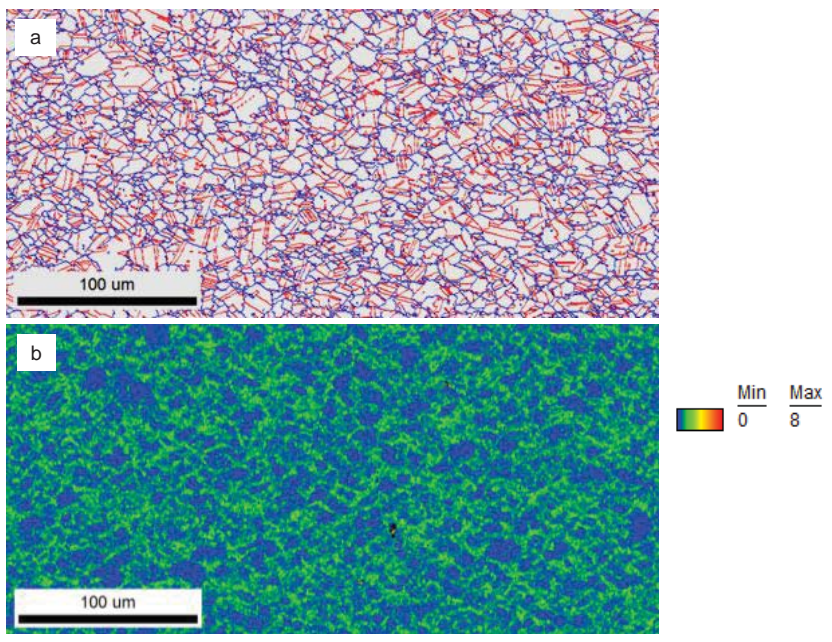

Figure 10. EBSD analysis at the strain position of 0.1 for the microstructure as-deformed at $980{ }^{\circ} \mathrm{C}$ to $10 \%$ reduction for a nominal strain rate of $0.5 \mathrm{~s}^{-1}$

(a) Grain boundary image, (b) KAM map
Figure 11 shows EBSD data around the strain position of 0.05 in Figure 3a-b, implying that the measurement area is near the boundary between AGG region and no AGG region. The changes of microstructure caused by AGG are as follows.

(1) Coarsening of fine grains

(2) Increase in twin boundary density

(3) Decrease in misorientation

Especially, the decrease in misorientation by AGG is less toward smaller strains because the misorientation as-deformed condition offers gradient. In addition, the misorientation doesn't decrease so much in the no AGG region during solution heat treatment.

To understand AGG progress, microstructural change with annealing time was investigated. Figure 12 shows EBSD data for the microstructures as-deformed conditions at $980{ }^{\circ} \mathrm{C}$ to $10 \%$ reduction and subsequent annealing at $980{ }^{\circ} \mathrm{C}$ for $0,10,20,60$ and $240 \mathrm{sec}$ before cooling. Annealing time $0 \mathrm{sec}$ is the same condition as Figure 3a, namely rapid cooling immediately after deformation. Grain growth originates from around the strain position of 0.1 in early stage and then proceeds toward smaller strains with annealing time. Moreover, AGG is remarkable with decreasing strain. The change of twin boundary density is comparable to that of grain size.

On the other hand, misorientation decreases mainly around the strain position of 0.1 in an early stage, thereby yielding contrary gradient of misorientation compared to as-deformed condition. Then the decrease in misorientation proceeds toward smaller strains with annealing time. 

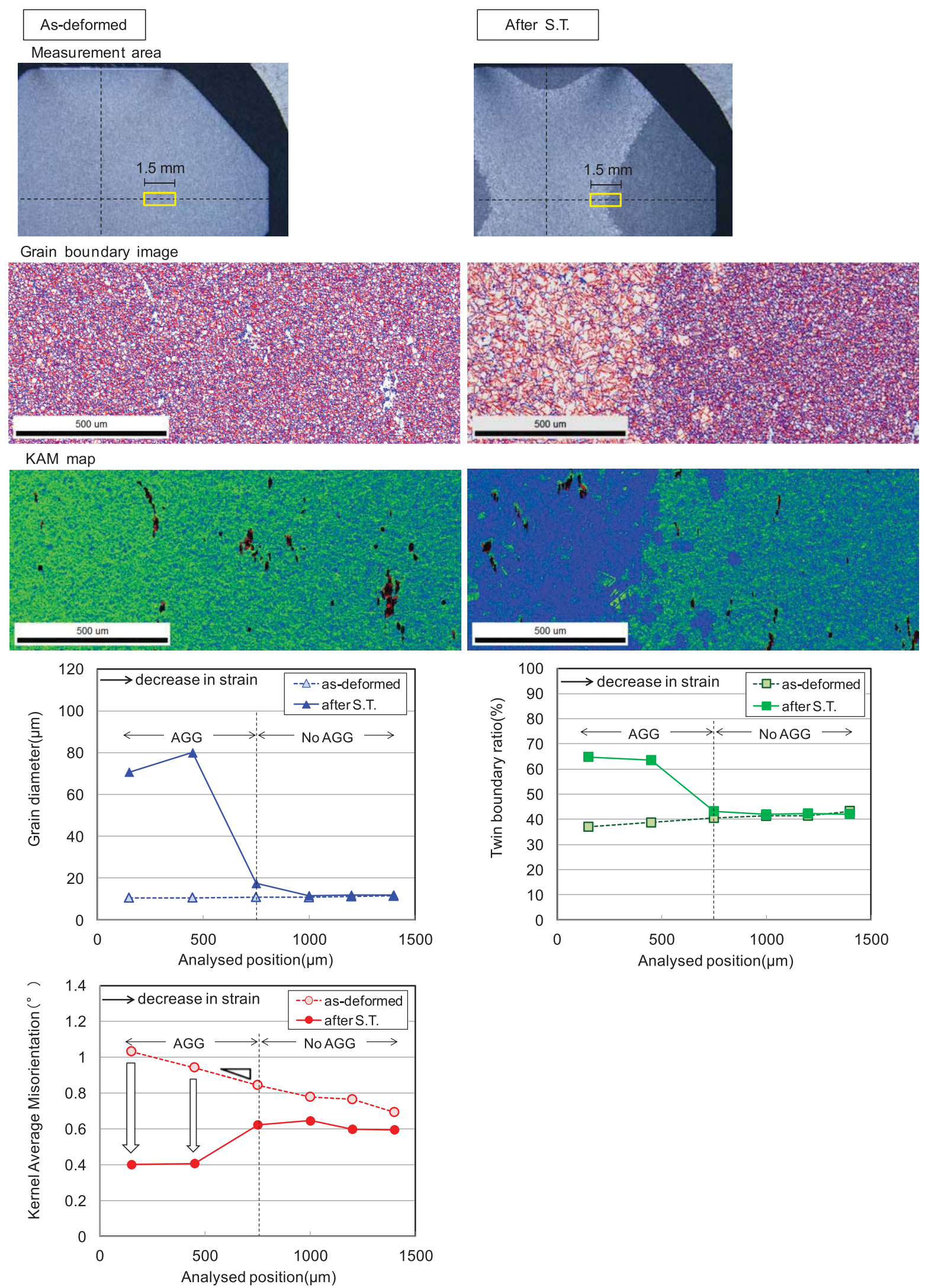

Figure 11. EBSD analysis around strain position of 0.05 for the microstructure as-deformed at $980{ }^{\circ} \mathrm{C}$ to $10 \%$ reduction for a nominal strain rate of $0.5 \mathrm{~s}^{-1}$ and for that after solution heat treatment at $980{ }^{\circ} \mathrm{C}$ for $1 \mathrm{hr}$ 

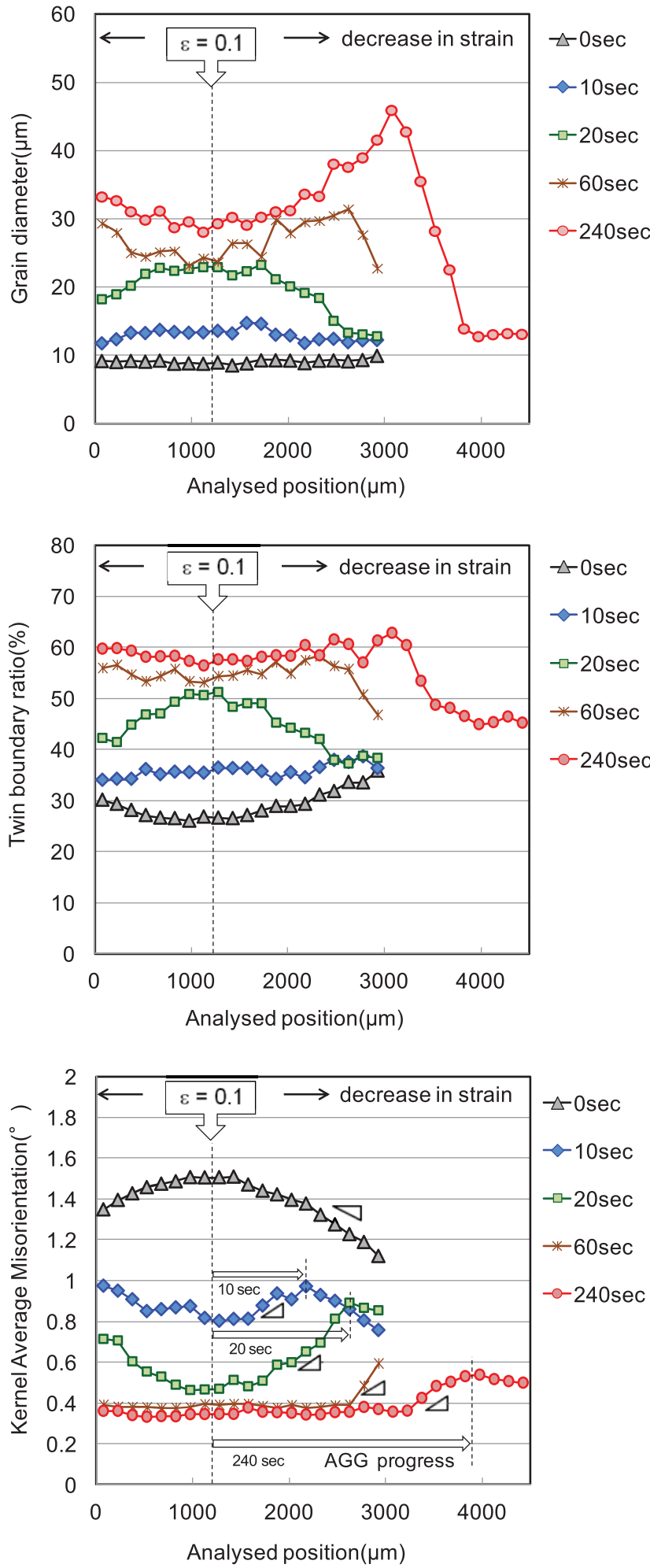

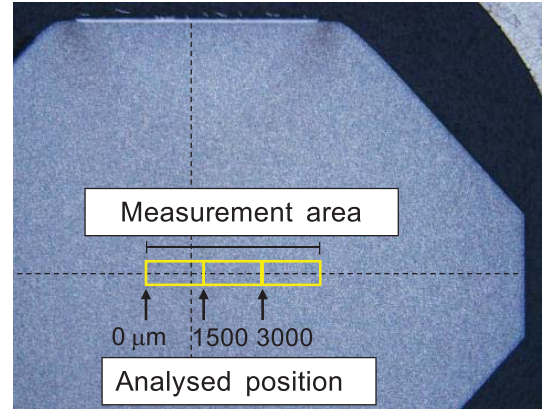

KAM map
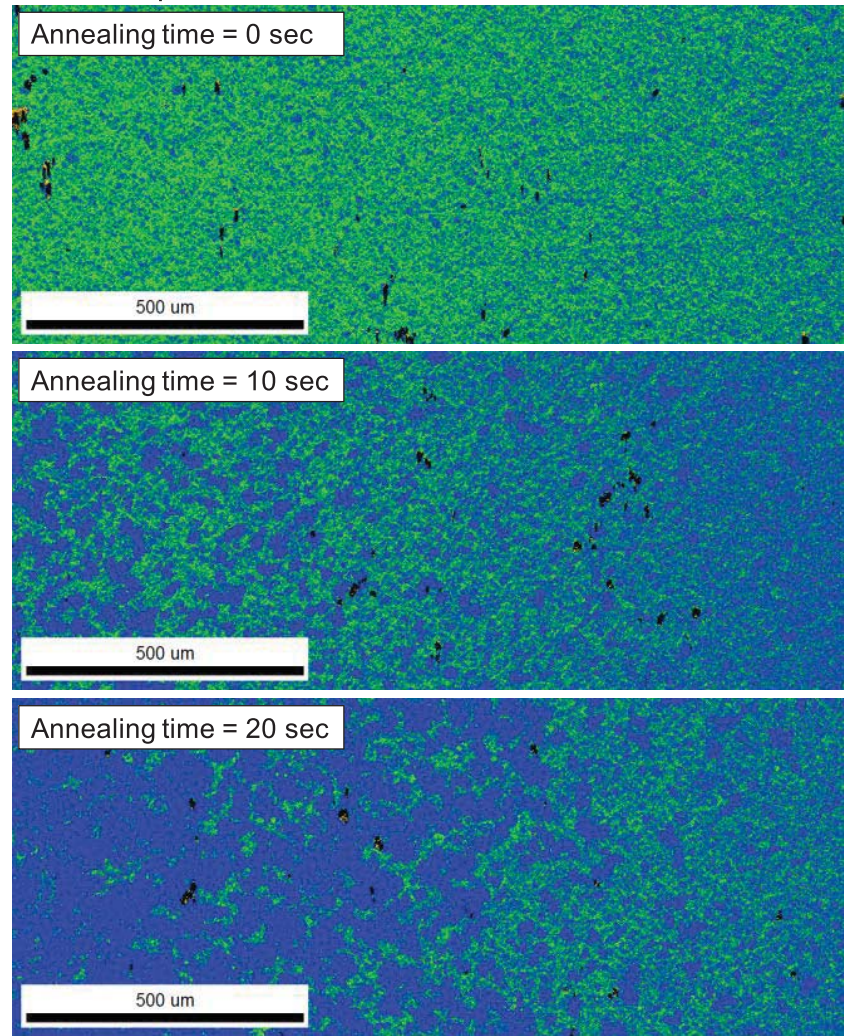

Annealing time $=60 \mathrm{sec}$

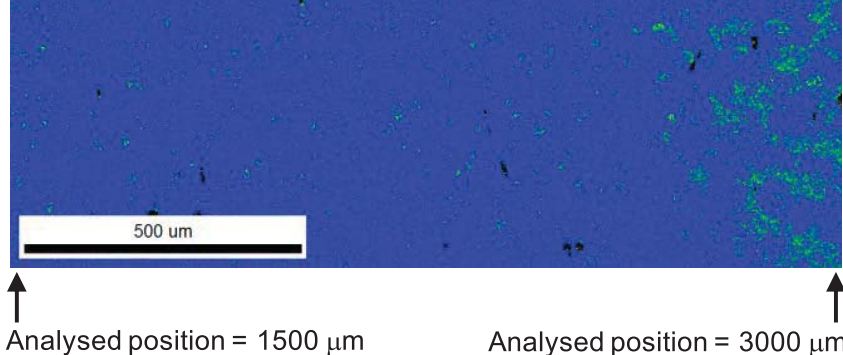

Analysed position $=1500 \mu \mathrm{m}$

Analysed position $=3000 \mu \mathrm{m}$

\section{AGG progress}

Figure 12. EBSD analysis for the microstructures as-deformed conditions at $980{ }^{\circ} \mathrm{C}$ to $10 \%$ reduction for a nominal strain rate of $0.5 \mathrm{~s}^{-1}$ and subsequent annealing at $980^{\circ} \mathrm{C}$ for $0,10,20,60$ and $240 \mathrm{sec}$ before cooling 
From the results of Figure 10-12, AGG behavior is summarized as follows.

(1) Misorientation concentrates near grain boundary.

(2) Grain growth starts in the region of higher misorientation.

(3) AGG progress involves both the decrease in misorientation and the increase in twin boundary density.

(4) AGG becomes remarkable as it proceeds.

\section{Discussion}

It was found that AGG progressed from larger strains toward smaller strains, with decreasing misorientation which concentrates near the grain boudaries and increasing twin boundary density, as can be seen from Figure 10-12. Figure 13ad illustrate a model for AGG occurrence and progress during thermal process such as solution heat treatment, annealing and slow cooling from deformation. In the strain range where no recrystallization results, the stored energy becomes higher with increasing strain (Figure 13a). When the stored energy exceeds a certain critical level, it begins to decrease by recovery during thermal process. This yields a contrary gradient of stored energy compared to as-deformed condition, and a sharp gradient between recovery region and no recovery region (Figure 13b). It is considered that this gradient generates a driving force for grain boundary migration which proceeds toward higher stored energies. The local boundary migration also results in providing the next driving force, leading to boundary migration progress (Figure 13c). Once strain induced boundary migration (SIBM) occurs, it continues until the driving force becomes low enough (Figure 13d), as can be seen from graphs of KAM in Figure 1112. Consequently, it is considered that AGG originates on the conditions that fine-grain structure has a gradient of stored energy and the stored energy decreases through recovery.

On the other hand, lower strain rate easily led to grain growth (IGG) during solution heat treatment after deformation, as can be seen from Figure 6-8. The feature of this behavior includes that grain growth is distinct compared to that for higher strain rates. It is possible that IGG is attributed to discontinuous dynamic recrystallization. It is considered that discontinuous recrystallization causes the local variation in the distribution of stored energy, which results in the local SIBM, namely IGG.
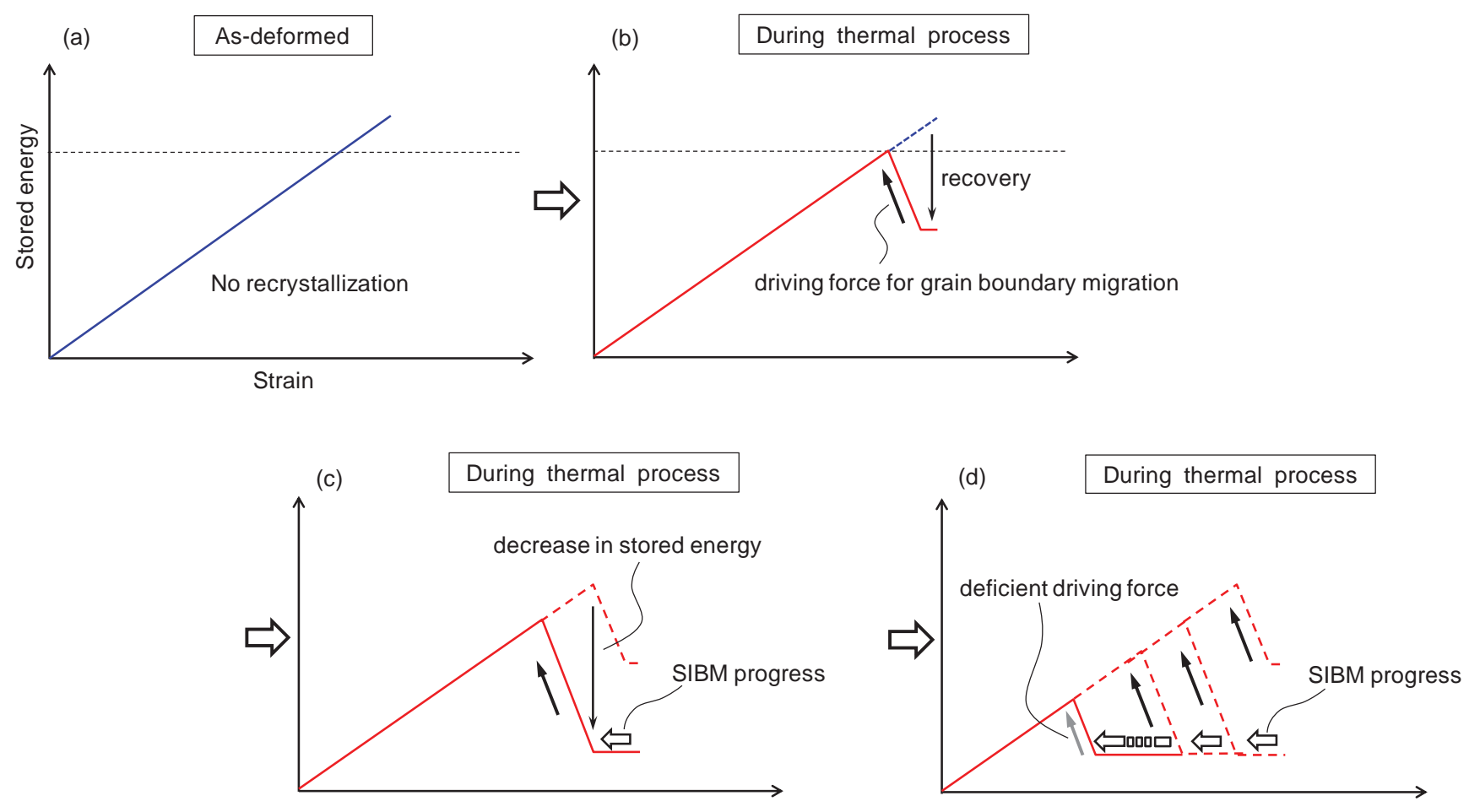

Figure 13. A model for AGG progress

(a) as-deformed, (b)(c)(d) during thermal process after deformation 


\section{Conclusions}

The grain growth behavior of Alloy 718 with initial grain size of ASTM 10 was investigated through compression tests and subsequent thermal process. The results are summarized as follows.

1. AGG occurs during solution heat treatment after deformation, annealing and slow cooling immediately after deformation for the case of imposing a small strain which doesn't yield recrystallization. AGG results in changing the fine-grains with a diameter of about $10 \mu \mathrm{m}$ into the coarsegrains with a diameter of about $80 \mu \mathrm{m}$ beyond the $\delta$ particles.

2. The strain range in which AGG occurs shifts to larger strains and extends with a decrease in strain rate. Particularly, deformation at a low strain rate of the order of $10^{-3} \mathrm{~s}^{-1}$ easily leads to grain growth (IGG) during solution heat treatment, over the strain range even where recrystallization occurs.

3. AGG proceeds toward smaller strains while involving an increase in twin boudary density and a decrease in misorientation. It is possible that AGG results from continuous SIBM which starts with local recovery.

\section{References}

1. J. F. Uginet, B. Pieraggi, "Study of secondary grain growth on 718 Alloy", Superalloys 718, 625, 706 and Various Derivatives, ed. E. A. Loria, (Warrendale, PA: TMS, 1997), 343-352.

2. R. Watson, M. Preuss, J. Quinta de Fonseca, T. Witulski and G. Terlinde, "The effect of strain and temperature profiles on static recrystallization during solution heat treatment after hot deformation of Alloy 718", Superalloys 718, 625, 706 and Various Derivatives, ed. E. A. Loria, (Warrendale, PA: TMS, 2014), 873-884.

3. R. Schwant, S. Thamboo, L. Yang and M. Morra, "Extending the size of Alloy 718 rotating components", Superalloys 718, 625, 706 and Various Derivatives, ed. E. A. Loria, (Warrendale, PA: TMS, 2005), 15-24.

4. B. Flageolet, O. Yousfi, Y. Dahan, P. Villechaise and J. Cormier, "Characterization of microstructures containing abnormal grain growth zones in Alloy 718", Superalloys 718, 625, 706 and Various Derivatives, ed. E. A. Loria, (Warrendale, PA: TMS, 2010), 595-606.

5. E. Huron, S. Srivatsa, E. Raymond, "Control of grain size via forging strain rate limits for R'88DT", Superalloys 2000, eds. T. M. Pollock et al., (Warrendale, PA: TMS, 2000), 49-58.

6. Y. K. Cho, D. Y. Yoo and M. F. Henry, "The effects of deformation and pre-heat-treatment on abnormal grain growth in René 88 superalloy", Metallurgical and Materials Transactions A, 32A (2001), 3077-3090.
7. A. Agnoli, M. Bernacki, R. Logé, J. M. Franchet, J. Laigo and N. Bozzolo, "Understanding and modeling of grain boundary pinning in Inconel 718", Superalloys 2012, eds. E. S. Huron et al., (Warrendale, PA: TMS, 2012), 73-82.

8. A. Agnoli, M. Bernacki, R. Logé, J. M. Franchet, J. Laigo and N. Bozzolo, "Selective growth of low stored energy grains during $\delta$ sub-solvus annealing in the Inconel 718 nickel-based superalloy", Metallurgical and Materials Transaction A, 46A (2015), 4405-4421.

9. P. R. Bhowal, J. J. Schirra, "Full scale gatorizing ${ }^{\mathrm{TM}}$ of fine grain Inconel 718", Superalloys 718, 625, 706 and Various Derivatives, ed. E. A. Loria, (Warrendale, PA: TMS, 2001), 193-201. 